\title{
Gellner, A Educação E Os Organismos Multilaterais
}

Francisco AdJacy Farias

Resumo: À luz da teoria do nacionalismo de Ernest Gellner, reflito sobre as transformações do sistema de ensino na sociedade ocidental desde o século XIX. Suas ideias fundamentam a análise da ingerência exercida pelos organismos multilaterais, mais especificamente o BID e o Banco Mundial, nas políticas educacionais, a partir da década de 1990, tendo por base o documento denominado "Educação um tesouro a descobrir".

Palavras-chave: Educação; Pobreza; Multilateralismo; Nacionalismo; Gellner.

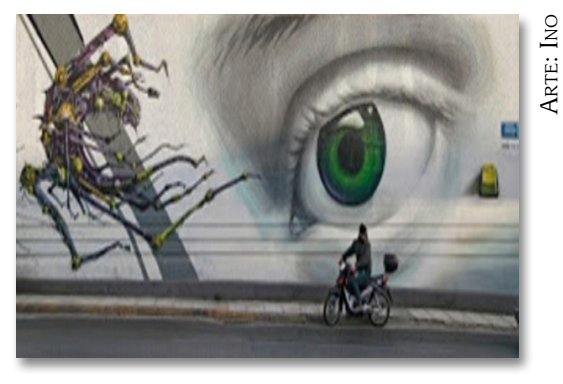

\section{Gellner, the education and multilateral organizations}

\section{Francisco Adjacy Farias}

Mestre em Sociologia pela UECE e pesquisador do Observatório das Nacionalidades. adjacy@yahoo.com.br
Abstract: In the light of Ernest Gellner's theory of nationalism, the author reflects on changes in the educational system in Western society since the 19th century. Gellner's ideas support an analysis of the interference on educational policies from the early 1990s of multilateral organizations, in particular the IDB and the World Bank. It is based on the document entitled "Education a Treasure to Discover".

Keywords:Education; Poverty; Multilateralism; Nationalism; Gellner

\begin{tabular}{c}
$\overline{\text { ReCEBIDO EM } 28-01-2015}$ \\
\hline Aprovado EM $22-05-2015$
\end{tabular} 


\section{INTRODUÇÃO}

Os estudos do filósofo e antropólogo Ernest André Gellner (1925-1995), de uma forma geral, têm gerado forte contribuição teórica para entendermos o surgimento e desenvolvimento da principal instituição política do mundo moderno: o Estado-Nação. Contanto, Gellner analisa o sistema educacional como elemento fundamental nas transformações ocorridas no desenvolvimento do capitalismo a partir do século XIX, classificando-O como o principal agente social na "construção de novas mentes".

A década de 1990 foi um período marcante em termos de expansão no processo de desenvolvimento. Nesse cenário da política global, podemos destacar a atuação de organismos multilaterais, como o Banco Interamericano de Desenvolvimento (BID), o Fundo Monetário Internacional (FMI), o Banco Mundial (BM), a Organização Mundial do Trabalho (OMC), etc. Essas instituições têm gerado forte influência no direcionamento de políticas públicas nas mais diversas áreas sociais e, consequentemente, em governos nacionais, sobretudo através de programas socioeconômicos elaborados e implementados por esses organismos como forma de estabelecer os denominados "ajustes estruturais". Nesse cenário, os programas educacionais, com efeito, se entrelaçam às ações dessas instituições no combate à pobreza, visto que a "erradicação da pobreza" é um dos principais objetivos do BM e do BID. O vínculo entre tais programas é amplo e diverso, porém esse artigo destaca parcialmente um deles denominado "Educação um tesouro a descobrir", visto a relevância deste diante o panorama educacional.

Entre as transformações percebidas por Gellner na transição de uma sociedade agro-letrada para outra de cunho industrial-urbana / capitalista, destacamos aqui a "semantização do trabalho", a "homogeneidade social", a "estandardização da educação" e a prevalência de uma "cultura superior" liderada por uma "elite dominante", denominações escolhidas pelo autor para acentuar fenômenos socioculturais que estariam estreitamente relacionados às mudanças que a educação sofreu com o desenvolvimento da então emergente sociedade industrial /capitalista. Esse artigo 
tenta atualizar tais fenômenos, relacionando-os à atual política global.

A primeira parte, "Unidade trabalho-educação e universalização do ensino", traz um panorama geral, discutindo características universais que a Educação adquiriu com o desenvolvimento do capitalismo, a partir do pensamento gellnersiano, para em seguida expor o documento "Educação um tesouro a descobrir", que exemplifica bem a articulação dos organismos internacionais na área educacional.

A segunda parte, "Capital humano: educação para os pobres" aborda as intervenções dos organismos internacionais BID e Banco Mundial na área educacional a partir dos anos de 1990, como parte das transformações globais, para assim discutir funções da educação no capitalismo.

Visto a relevante implicância do sistema educacional no ininterrupto e mutante processo de construção das nações, este artigo tenta contribuir no prolífero campo de estudos ainda pouco explorado pelas ciências sociais.

\section{UNIDADE TRABALHO-EDUCAÇÃO E UNIVERSALIZAÇÃO DO ENSINO}

Com o advento da revolução industrial e do seu desenvolvimento ao longo do século XIX, as transformações ocorridas numa sociedade econômica, social e politicamente turbulenta surtiram relevantes efeitos nas ideias, nas artes, na academia e nas ciências humanas de forma geral. A expansão da sociedade capitalista industrial durante o século XX amplia as funções da educação: direito humano, bem de consumo, instrumento de transmissão de valores e meio de elevar a produção de bens. A corrida capitalista em busca de angariar novos mercados consumidores acentua a distinção entre uma educação formadora de saberes e outra produtora de mão-de-obra.

Portanto, no início do século XX, além de mudanças econômicas (impulsionadas pelo desenvolvimento capitalista), houve simultaneamente uma série de novos pensamentos, teorias e práticas nas diversas áreas do conhecimento: filosofia, sociologia, 
artes, direito, economia, etc. A educação não foge à regra e acompanha a complexidade do mundo moderno. As transformações na educação fazem parte do macroprocesso de transição que teve início com a passagem da sociedade agrária à sociedade industrial, que Ernest Gellner estudou para entender o surgimento da nação moderna. Gellner ressalta características da transmutação da antiga sociedade agro-letrada para uma sociedade industrial avançada, que se acentuaram a partir do século XIX na Europa ocidental, tais como "semantização do trabalho", "homogeneidade social", "estandardização da educação" e a prevalência de uma "cultura superior" liderada por uma "elite dominante". Esses fatores estão intrinsecamente relacionados às mudanças que a educação sofreu com o desenvolvimento da sociedade industrial capitalista. Conforme o modelo teórico formulado por Gellner, o sistema educacional é crucial para compreender a "grande transformação" que, no mundo ocidental, daria origem ao nacionalismo (GELLNER, 2000). "O sistema educacional torna-se uma parte extremamente importante dela (sociedade industrial) e o papel principal da educação passa a ser a manutenção do meio cultural/ linguístico" (GELLNER, 1993, p. 56).

As antigas sociedades agro-letradas eram compostas de camadas sociais descentralizadas, sendo a educação gerada em unidades independentes e de forma mais direta (de pai para filho). Nesse tipo-ideal de sociedade prevalecia o trabalho manual, a "tecnologia estável", as culturas distintas em um mesmo território/região e a educação baseada na transmissão hereditária - o que a tornava inadequada à homogeneização de um sistema educacional com características universais (GELLNER, 2000).

Com a emergência da sociedade industrial avançada surgem as noções de progresso, "tecnologia instável", expectativa de crescimento prolongado, divisão do trabalho móvel, comunicação ampla e contínua, idioma "estandardizado", entre outras características que requeriam um novo tipo de educação:

O nível de instrução e de comunicação técnica num meio de comunicação estandardizada, numa moeda conceitual comum, tal como exigido aos membros dessa sociedade se quiserem ser devidamente empregados e gozar de sua cidadania total e real, é tão elevado que, simplesmente, 
não pode ser fornecido pelas unidades de parentesco ou locais. Apenas pode ser fornecido por algo que se assemelhe ao sistema educacional nacional moderno [...] (GELLNER, 1993, p. 58).

O autor destaca a emergência de uma cultura erudita na sociedade industrial que induz à "unificação de ideias em sistemas contínuos e uniformes" (GELLNER, 1993, p. 41). Com efeito, a dimensão sociopolítica dessa nova comunidade nacional requer uma "intelligentsia" que a sistematize como "alta cultura" e um sistema educacional centralizado que aperfeiçoe sua transmissão. Observou ainda que a educação adequada a essa sociedade industrial requeria saberes sistematizados para atender os interesses de uma coletividade orientada ao mercado (GELLNER, 1993).

Na sociedade agro-letrada, os saberes de cada região eram transmitidos de forma mais heterogênea, devido à diversidade cultural dentro de um mesmo território político - no caso, os grandes reinados. O bom domínio das letras e a alfabetização eram restritos a poucos cidadãos; a maioria da população recebia uma educação fundamentada na vivência cotidiana. Mas, apesar da "boa educação" ser insígnia de status social, as elites dessa época "nunca podem efetivamente ser bem-sucedidas, pela simples razão de que tais sociedades não possuem meios para tornar a alfabetização quase universal e para incorporar as grandes massas populares numa cultura erudita, concretizando dessa forma os ideais da elite letrada" (GELLNER, 1993, p. 25). Já na sociedade industrial avançada a educação é centralizada no poder do Estado, em oposição aos ensinamentos pulverizados nas subculturas do modelo anterior.

Pode-se dizer que nas sociedades agro-letradas havia uma educação endógena, onde as pequenas comunidades tinham poder de auto-reprodução, com maior capacidade de intersecção entre si; enquanto nas sociedades industriais, a educação tornou-se independente e externa (educação exógena), com características universais, sob a égide de uma cultura erudita superior. Para Gellner, a sociedade moderna transforma:

[...] todos em 'letrados, fazendo desta classe potencialmente universal, e assegurando que todos, sem exceção, sejam ensinados por ela. A educação vinda do exterior (exo-educação) 
transforma-se, assim, na norma universal, de modo que ninguém do ponto de vista cultural, faz a barba a si próprio. A sociedade moderna é aquela em que qualquer subcomunidade, abaixo da dimensão daquela que é capaz de manter um sistema educacional independente, já que não pode autoreproduzir-se. A própria reprodução de indivíduos totalmente socializados passa a fazer parte da divisão do trabalho, deixando as subcoumunidades de desempenhar essa tarefa (GELLNER, 1993, p. 55).

A sociedade industrial é organizada a partir de um modelo econômico que busca homogeneidade social a ser concretizada com a uniformização de uma língua "nacional" e de sistemas de ensino "nacionais". O autor atribui um papel modernizador às elites intelectuais, que se utilizam da rede educacional para construir uma nação moderna. A referida "cultura superior", representada pela classe dominante, sobrepõe-se às culturas ditas "inferiores" ou "atrasadas", em referência às antigas sociedades agro-letradas (GELLNER, 1993).

Nesse contexto, destacamos o papel da elite ao fomentar uma "cultura superior padronizada", o que prejudicou a intercomunicação e intersecção entre as subcomunidades de outrora, instituindo-a como única forma de "legitimação" para aos cidadãos:

A sociedade inteira deve ser perpassada por uma só cultura superior padronizada, caso pretenda funcionar. Ela já não pode tolerar uma proliferação desordenada de subculturas internas, todas presas ao contexto seriamente inibidas em sua intercomunicação mútua. O acesso à cultura superior apropriada e a aceitabilidade dentro dela são o bem mais importante e valioso das pessoas: ele instaura uma condição de acesso não apenas ao emprego, mas a cidadania legal e moral e a todos os tipos de participação social (GELLNER, 1993, p. 62).

Um fato sem precedentes, pois "pela primeiríssima vez na história da humanidade, uma cultura superior torna-se a cultura difundida, a cultura operacional de toda uma sociedade" (GELLNER, 2000, p. 116). Tal busca incessante por cidadania legal, emprego, moralidade, etc., ainda é bem presente na sociedade contemporânea, na qual prevalece a ordem de "ter" sobre o "ser" impulsionada pelo consumismo exacerbado promovido pelo atual sistema produtivo. 
Gellner aborda também as implicações da sociedade industrial sobre o trabalho. É o que ele define como "semantização do trabalho". ${ }^{1}$ Isso significa a existência de um sistema composto por uma classe de trabalhadores que depende de uma escolarização formal (educação sistemática e prolongada) para garantir sua especialização e, consequentemente, sua vaga no emprego. Portanto, a transição de uma economia agrária para outra industrializada requer uma nova estrutura ocupacional que exige uma mão de obra especializada; daí a necessidade de uma educação "estandardizada". Desse modo, os trabalhadores tornaram-se dependentes de uma educação orientada pelas demandas do capital.

Todas as características ressaltadas por Gellner para definir essa nova sociedade industrial, regida pela economia de mercado e por uma educação "estandardizada", com destaque para o forte nacionalismo, ainda permanecem bem vivas na atualidade e são potencializadas com o desenvolvimento das relações multilaterais (pós II Guerra) e o processo de globalização.

Rodriguez (2013) observa as mesmas características de Gellner ao analisar a relevância da educação, a predominância de uma elite e a noção incessante de progresso no desenvolvimento da sociedade moderna e dos Estados-nação do século XX:

A educação é o instrumento modernizador ideal que irá alavancar o progresso e consolidar os nascentes Estados Nacionais. No entanto, o crescente progresso propiciado pela revolução industrial coloca, às elites dominantes, a necessidade de controle e da estabilidade social que lhes permita desfrutar tranquilos os frutos do progresso (RODRIGUEZ, 2013, p. 75).

As tendências e modas do mundo contemporâneo estão diretamente relacionadas ao processo de mundialização do capital. Os meios de comunicação e mídia de massa (televisão, cinema, internet, etc) são usualmente acusados de proliferar valores dominantes

\footnotetext{
1 Semantização do trabalho significa transformação e sofisticação do trabalho resultantes da busca incessante por crescimento econômico e da inovação a partir da transição da sociedade agro-letrada para a indústria, onde o trabalho semântico contrasta com o trabalho de esforço físico, requerendo, assim, uma escolarização formalizada para todos os trabalhadores que pretendem integrar a estrutura ocupacional. (Nota do autor).
} 
e ideias questionáveis. Porém a educação formal geralmente não recebe a mesma atenção que normalmente atribuímos ao "quarto poder" (a mídia) na formação dos indivíduos. No entanto, os propulsores do capitalismo - organismos multilaterais, grandes empresas e bancos públicos internacionais - estão sempre bem atentos ao potencial formador e reprodutivo da educação.

Hoje, podemos atualizar as ideias de Gellner e denominar as grandes empresas transnacionais que impulsionam o capital mundial como as representantes da "elite superior" global. Estas têm todo interesse num sistema de ensino, que reproduza seus valores, em que a educação "estandardizada" seja um bom e rentável investimento. Os organismos multilaterais são os maiores promotores dessa "ordem mundial" e representantes de uma "elite global" que pretende a mesma "homogeneização" com a ajuda de uma educação planificada e "universalizada". Com efeito, o processo de automatização das empresas veio somente a potencializar a "semantização do trabalho", acirrando a competição por emprego, ao demandar serviços cada vez mais especializados e "abstratos".

A presença dos organismos internacionais na Educação é ampla e diversificada. Porém, para exemplificar esse tipo de interferência internacional neste estudo, destacaremos o "Relatório Delors", especificamente sobre os "Quatro Pilares", por representar um marco nos parâmetros da educação mundial.

Tal documento foi instituído a partir da conferência internacional de Jomtein, na Tailândia, em 1990, promovida pela Organização das Nações Unidas (ONU) e financiada pelo Banco Mundial, sob o tema "Educação para Todos". O evento contou com a presença de 150 países e de reconhecidas autoridades na área da educação. Podemos dizer que um dos rebatimentos das orientações saídas de Jomtien foi a constituição da Comissão Internacional sobre a Educação para o Século XXI, coordenada pelo pedagogo francês e consultor da ONU, Jacques Delors. A solicitação de convocação da referida Comissão se deu na Conferência Geral da Unesco, em 1991, sendo oficialmente criada em 1993. Entre os anos de 1993 e 1996, a Comissão elaborou o Relatório "Educação: um Tesouro a Descobrir" (1996), documento que contém, em seu capítulo 4, 
os princípios denominados "Os Quatro Pilares da Educação", os quais pretendiam dar novas diretrizes educacionais para o mundo ocidental (MAIA; JIMENEZ, 2013).

A afirmação e adoção do documento "Educação um tesouro a descobrir" marcam a trajetória das relações entre capitalismo e educação. A partir dele, parâmetros educacionais foram determinados e ajustados em consonância a um novo perfil trabalhista, sob a égide do capital mundial. Os "Quatros Pilares da Educação" foram instituídos para justificar as mudanças econômicas, políticas e sociais que ocorriam em escala global. Segundo a comissão de Jacques Delors, se buscavam soluções para dois problemas identificados nos processos educacionais do século passado: a hiper valorização dos aspectos cognitivos e práticos do saber (o "aprender a conhecer"), em detrimento de outras dimensões fundamentais do ser humano, e o apego a um modelo de formação ultrapassado (o "aprender a fazer"), baseado no aprendizado de conteúdos e habilidades mais ou menos estáveis, vinculados a uma determinada qualificação ou profissão (MAIA; JIMENEZ, 2013). Na busca da superação dessas duas práticas, de hipertrofia teórica e do tecnicismo operacional, o relatório sugere a adoção, por parte da escola, de duas outras práticas que, somadas às anteriores e em equilíbrio, seriam capazes de formar um ser humano apto a acompanhar as mudanças vertiginosas da contemporaneidade: o "aprender a conviver" e o "aprender a ser". Assim, a comissão apresenta o que seriam os "Quatro Pilares da Educação" (DELORS, 1998):

a) Aprender a conhecer - enfatiza a teoria, o conteúdo e a informação;

b) Aprender a fazer - facilita a operacionalização de tarefas;

c) Aprender a conviver - firma-se nas relações entre os seres humanos;

d) Aprender a ser - evidencia valores e atitudes como a solidariedade.

A primeira dimensão - "aprender a conhecer" - dominaria as atividades teóricas, a aprendizagem de conteúdos e de informações tecnicamente úteis, instrumentais. Esse "pilar" pretende 
superar tal dimensão por considerar que a escola tradicional focava em demasia o conteúdo, tornando-o excessivamente teórico, desligado da prática cotidiana, estático e descontextualizado. Argumenta que essa perspectiva excessivamente cognitiva não favorecia a pesquisa ou proporcionava uma visão mais abrangente do real.

A segunda dimensão - "aprender a fazer" - supervalorizaria as habilidades e encontra seu ápice nos modos de produção taylorista e fordista onde é a precisão de atividades repetitivas e mecânicas que possibilita os ganhos de produtividade.

A terceira dimensão - "aprender a conviver" - incentivaria a cooperação, atuaria no plano da convivência, transmitiria saberes sobre diversidade, semelhanças e interdependência entre povos para disseminar a solidariedade, possibilitaria o reconhecimento do outro, a partir do conhecer a si próprio.

A quarta dimensão - "aprender a ser" - seria pautada na integração do conhecimento para ultrapassar o tecnicismo e a padronização dos costumes e valores produzida pela mídia, incentivando os jovens ao pensamento crítico e autônomo.

Portanto, de forma geral os novos direcionamentos dos "quatros pilares" têm a pretensão de superar práticas e saberes da escola tradicional, considerada ultrapassada, estabelecendo novas necessidades educacionais para integrar os indivíduos à dita sociedade do conhecimento e da informação do século XXI. Essas diretrizes ficaram conhecidas sinteticamente como o novo "aprender a aprender" e sua aplicação exigiu reformas profundas no sistema educacional.

Segundo Maia e Jimenez (2013), o modelo proposto pela comissão de Delors, e especificamente as diretrizes dos "Quatro Pilares da Educação", apesar de aparentemente atrativo e tentador, está repleto de contradições e incongruências. Sua aplicação desconsidera as características e a lógica do atual sistema de produção capitalista, além de "oferecer uma resposta bastante simples a um problema deveras complexo" (MAIA; JIMENEZ, 2013, p. 123). A adoção de tais diretrizes educacionais reflete uma postura redentora da humanidade, se apoia em expressões como "conhecimento desinteressado" ou neutro, procura evitar discussões críticas 
sobre o uso e os fins políticos, práticos e mercantis do conhecimento científico, sendo apenas mais um recurso discursivo para a conservação do atual modo de produção capitalista.

O "aprender a conhecer" estaria desconectado da multiplicidade característica do processo de aprendizagem. Escamoteando o princípio fenomenológico do conhecimento cotidiano, os teóricos da ONU entendem o processo de cognição, sobretudo a educação formal, como o único modo admissível de conhecimento. Para atingir esse "conhecimento puro", o indivíduo teria que trilhar o caminho da "neutralidade científica", o que seria praticamente impossível dentro da realidade científica contemporânea. O "Aprender a fazer" inviabiliza elementos centrais na nova forma de organização do trabalho, como a criatividade e a inovação, e despreza totalmente o caráter cada vez mais imaterial dos bens e serviços. Diante de tais impasses, como incentivar as relações interpessoais em um ambiente de trabalho tão "imaterial"? O espírito de cooperação e solidariedade do "aprender a conviver" está em oposição à dinâmica conflituosa das relações entre as nações, permeadas por diferentes interesses e desproporcionalidades de riqueza e poder, assim como dos conflitos relacionados ao racismo e à intolerância entre os povos. O "aprender a ser" cai na contradição de defender um indivíduo "crítico e autônomo" no interior de um modelo econômico que fomenta a desumanização do ser humano, com uma evolução tecnológica contínua, com valores efêmeros instigados pela moda e pelo consumismo (MAIA; JIMENEZ, 2013).

Assim, os "pilares" trariam em suas contradições a tentativa velada de, apregoando a mudança, promover a manutenção de um sistema repleto de incoerências e contrassensos. Propriedades contrastantes em uma realidade onde o conhecimento dinâmico e relacional torna-se uma perspectiva geral e vasta, com indivíduos de conhecimentos sistêmicos, de leituras fragmentadas e mecânicas (MAIA; JIMENEZ, 2013).

Além disso, Maia e Jimenez (2013) encontram nesse modelo educacional o mesmo problema relacionado à "semantização do trabalho" que Ernest Gellner detectou em seus estudos; ou seja, a desvalorização do trabalho em função de uma cientificidade 
progressiva que a sociedade industrial, ou a sociedade do conhecimento, requer constantemente:

Como é sabido, tal paradigma pretende desqualificar o trabalho e, por conseguinte, as relações de classe, como referência central de organização de sociedade contemporânea, cuja configuração delineada pelo avanço tecnológico e comunicacional teria erigido a ciência - em lugar do trabalho ao posto de principal força produtiva (MAIA; JIMENEZ, 2013, p. 123).

Os autores atentam também ao fato de o modelo proposto pela comissão da ONU ser direcionado aos problemas setoriais da educação, sem levar em conta os ditames da macroeconomia. Essa questão pode ser ampliada se considerarmos, ainda, a diversidade e peculiaridade de cada país/cultura em que o modelo vem sendo implantado - tal como acontece aos programas de combate à pobreza. Então, em nenhum momento, os problemas indicados pela comissão fazem referência a essas e outras inúmeras dificuldades relacionadas à dinâmica do capitalismo.

Não é de estranhar que, assim os termos que definem o modelo proposto, em nenhum momento, façam referência explícita à totalidade econômica e político-social, cujo desenvolvimento histórico resultou no modo de produção capitalista que domina a sociedade moderna atual, ou estabelecem qualquer ligação explícita entre os dilemas do atual desenvolvimento capitalista e as determinações do modelo educacional que lhe é compatível (MAIA; JIMENEZ, 2013, p. 122).

Alertam, ainda, que o modelo dos Quatro Pilares está em contradição até mesmo com a consagrada corrente interacionista de Piaget $^{2}$ e com a perspectiva histórico-cultural de Vygostky ${ }^{3}$, por

2 A teoria cognitiva de Jean Piaget (1896-1980) adota abordagem interdisciplinar para a investigação epistemológica a partir da gênese psicológica do ser humano, representada pela sua "Teoria dos Estágios". Nela Piaget propõe a existência de quatro fases de desenvolvimento cognitivo: o sensório-motor, pré-operacional (pré-operatório), operatório concreto e operatório formal. Para ele, as crianças aprenderiam apenas o que estavam preparadas a assimilar e aos professores caberia aperfeiçoar o processo de descoberta dos alunos (LA TAILLE; DANTAS; OLIVEIRA, 1992).

3 Lev Vygotsky (1896-1934) desenvolve suas pesquisas no período pósrevolução na Rússia, inspirado no materialismo histórico dialético de Karl Marx e Friedrich Engels, construiu sua "Teoria do Desenvolvimento". Segundo 
essa priorizar a transmissão formal de conhecimento em si, desvalorizando outras formas de aprendizado contempladas nessas tradições.

[...] se há uma contribuição fundamental das modernas teorias de aprendizagem (em especial, das chamadas teorias interacionistas) é exatamente a de contribuir para a superação do modelo tradicional de educação, centrado apenas na transmissão de saberes já produzido (MAIA; JIMENEZ, 2013, p. 123-124).

A transformação de macroprojetos internacionais dessa natureza em políticas de educação pode gerar conflitos nos países que as adotam, seja pelo processo de negociações com os governos nacionais, seja pelo choque de tais diretrizes educacionais com a diversidade, seja pela peculiaridade de cada comunidade/população sujeita a tais políticas. Os programas educacionais enfrentam, portanto, limitações semelhantes aos modelos de programas de combate à pobreza do BM, que ao serem implantados em alguns países (como na África subsaariana, por exemplo) não tiveram nenhum sucesso devido à repulsa dos beneficiários e ao contraste com as realidades locais (FARIAS, 2007).

Como visto, as diretrizes educacionais ditadas pelos organismos multilaterais são polêmicas e têm provocado críticas dos especialistas da área. Contudo, o discurso neoliberal tenta apaziguá-las com o uso de verbetes tais como "capacitações, qualificações, reciclagens, flexibilidade, criatividade, polivalência, trabalho em equipe, etc." na tentativa de instituir novas "competências e habilidades" da educação para o mundo do trabalho. Na realidade, representam uma violação disfarçada aos direitos dos trabalhadores.

Então, no presente estudo, a referência a esse documento da ONU reflete as implicações na instância educativa da lógica de desenvolvimento dos bancos públicos internacionais, com fins de atribuir à educação um papel de redenção social, revelando-se,

Vygotsky, o aprendizado do indivíduo resulta de um processo sócio-histórico, por considerar as contribuições da cultura, interação social e dimensão histórica do desenvolvimento mental (LA TAILLE; DANTAS; OLIVEIRA, 1992). 
portanto, como um significante instrumento de reprodução do capital.

No contexto das políticas neoliberais, a educação apresenta-se como mecanismo para essa "redenção social". E a estratégia do capital para apaziguar o fenômeno da pobreza é investir nas escolas, fazendo crer que a educação formal direcionada aos pobres irá resolver todas as contradições do sistema produtivo. Apesar de a pobreza ser um fenômeno multifacetário e inerente à lógica capitalista, no discurso neoliberal "ser pobre" é sinônimo de "incapaz" por não possuir "qualificação técnica e teórica". Daí a necessidade de inventar o "capital humano" e reinventar uma "educação para os pobres".

\section{3 “CAPITAL HUMANO", A EDUCAÇÃO PARA OS POBRES.}

O final da II Guerra Mundial transfere o centro de poder da Europa para os EUA, trazendo mudanças significativas na geopolítica mundial e no direcionamento da economia capitalista. A Guerra Fria acirra a disputa por "formadores de mentes" e formuladores de ideias, estimulando a expansão do capitalismo em todas as regiões do globo. Nesse âmbito, a educação, mais do que nunca, transforma-se num disputado instrumento político, tanto para a reprodução de valores e práticas, quanto para adaptação dos indivíduos ao "mundo moderno". Nas palavras atinadas de Gellner, "a principal indústria é a de formação de seres humanos aptos à sociedade" (GELLNER, 2000, p. 119). Essa sociedade emergente tende a padronizar a educação, utilizando-a a favor de uma "cultura superior" que seja aceitável e acessível a todos: "O sistema educacional padronizado que processa todo o material humano formador da sociedade, que transforma a matéria-prima biológica num produto cultural aceitável e útil, é imenso e extremamente dispendioso" (GELLNER, 2000, p. 119).

A nova ordem internacional fomenta uma sociedade marcada pela "mercantilização" da educação e pela influência das forças produtivas nos currículos escolares. A tecnocracia e o mecanicismo de hábitos "modernos" são vistos como estratégias a moldar as diretrizes educacionais no processo de mundialização do capital. 
O processo por meio do qual se constitui a tecnificação da educação conta, para sua realização, com a contribuição de diferentes organismos que se empenham, em âmbito internacional, na ajuda ou cooperação ao 'desenvolvimento' econômico-social e educacional (EVANGELISTA, 1997, p. 13).

A promessa dos defensores do atual sistema produtivo de que o desenvolvimento econômico e o progresso trariam o bem-estar social e, consequentemente, um mundo menos desigual e injusto, é antiga, mas ainda pertinente à retórica capitalista. Com efeito, a erradicação da pobreza tornou-se o grande desafio de governos e sociedade civil, e a "dobradinha" pobreza/educação surge como uma "panacéia" para solucionar esses problemas socioeconômicos. Os propulsores dessa lógica já entenderam que não se pode mais limitar o fenômeno da pobreza a fatores essencialmente econômicos para promover desenvolvimento e o amparo social às populações. Contudo, a utilização de padrões economicistas, como o Produto Interno Bruto (PIB), por exemplo, ainda é uma prática bem comum e universal para se medir a produção e distribuição de riqueza das nações. Porém, estudos sociológicos, filosóficos e econômicos têm aberto novos horizontes e contribuído bastante para a compreensão e a "práxis" efetiva do combate às causas da pobreza, ensejando o embate entre ideias de caráter social e humanitário versus aquelas utilitaristas e pragmáticas na tentativa de solucionar esse fenômeno social.

Nesse contexto, os organismos multilaterais têm apostado em suas políticas de "erradicação da pobreza" e na disseminação de conceitos como o dito "capital humano"4 ou "capital social"5. Desde os anos 1990 e durante a década de 2000, as práticas econo-

4 "Capital humano" é o conjunto de capacidades, conhecimentos, competências e atributos de personalidade que favorecem a realização de trabalho de modo a produzir valor econômico. São os atributos adquiridos por um trabalhador por meio da educação, perícia e experiência.

5 Há uma grande variedade de definições inter-relacionadas do termo "capital social". Tais definições tendem a partilhar a ideia central de "que as redes sociais têm valor econômico". Da mesma maneira que uma chave de fenda (que é um exemplo de capital físico) ou a educação escolar (que é formadora de "capital humano") podem aumentar a produtividade de indivíduos e organizações, os contatos sociais e a maneira como estes se relacionam também são fatores de desenvolvimento econômico. 
micistas predominantes têm cedido ao discurso de que o investimento no "capital humano" seria a grande estratégia desses organismos na promoção de seu ideário capitalista, porém sem que o motor propulsor do sistema - o consumo e a concentração de renda - seja afetado. Mesmo cedendo a um discurso de caráter mais humanitário, com a inclusão do "capital humano" em seus projetos e programas sociais (sobretudo os educacionais), a questão ainda assim permanece complexa, como ressalta Margarita Lopez:

[...] Quando se aborda a questão educacional em relação ao fortalecimento do capital social e com sua incidência na pobreza, não basta garantir o acesso à educação ou a oportunidade educativa como tal; numa análise mais fina, aparecem novos elementos que se tornam fundamentais para que a educação oferecida em uma sociedade possa ser útil para a diminuição da pobreza e da exclusão. Trata-se principalmente de questões como a qualidade, a pertinência e a equidade na educação (LOPEZ, 2005, p. 9).

O malogro neoliberal em "erradicar a pobreza" nos anos 1990 e a preocupação generalizada com a pertinência dos elevados índices de pobreza impulsionaram os bancos públicos internacionais a redefinirem a preleção em favor do "capital humano" e focalizar a educação como "solução" mágica para erradicar esse fenômeno social. Essa talvez seja a mais recente estratégia dos organismos multilaterais para prosseguir o plano de reformas estruturais, do qual são protagonistas.

O Banco Mundial, por exemplo, deixa bem clara a sua posição em relação à pobreza e à educação:

A educação é o maior instrumento para o desenvolvimento econômico e social. Ela é central na estratégia do Banco Mundial para ajudar os países a reduzir a pobreza e promover níveis de vida para o crescimento sustentável e investimento no povo. Essa dupla estratégia requer a promoção do uso produtivo do trabalho (o principal bem do pobre) e proporcionar serviços sociais básicos para o pobre (WORLD BANK, 1990).

Então, a "dupla estratégia" pobreza/educação vai se definindo, cada vez mais, na orientação ao "desenvolvimento e crescimento sustentável" ao longo da década de 2000, se estendendo até os dias atuais. Vale atentarmos para o discurso do BM que sustenta "O uso 
produtivo do trabalho" como o "principal bem do pobre" e a única arma capaz de livrá-los da carência de serviços básicos sociais, que outrora eram obrigações do Estado; ou seja, o neoliberalismo atribui as causas da pobreza à situação de cada indivíduo, que é "mal-educado" e "incapaz" de se adaptar ao trabalho, e nunca aos problemas estruturais do sistema produtivo (WORLD BANK, 1990).

Segundo Leher (1999), nos documentos dos organismos multilaterais, o fator "segurança" também está intimamente relacionado à educação e à pobreza. A "fragilidade", "insegurança" e "desqualificação" dos pobres seriam os principais motivos da sua não inserção no mercado de trabalho e da situação de carência que os cerca.

As conexões entre educação, segurança e pobreza fornecem o substrato das reformas educacionais em curso na América Latina. Com aprofundamento sem precedentes da polarização na década de 1990, o Banco Mundial dedica cada vez maior atenção à construção de instituições adequadas à era do mercado, de modo a ter recursos institucionais para 'manejar' as contradições do sistema. A educação é radicalmente modificada, tornando-se cada vez menos politécnica (no sentido conferido por Marx) e cada vez mais instrumental: os conteúdos estão fortemente carregados de ideologias apologéticas ao capital e o debate educacional é pautado em grande parte pelos 'homens de negócios' e pelos estrategistas políticos (LEHER, 1999, p. 11).

Ao longo da década de 2000, a onda de privatizações que proliferou no Brasil banalizou o ensino superior e reflete incursões neoliberais na educação brasileira. A propagação excessiva de faculdades e universidades privadas vem modificando significantemente a estrutura educacional. A educação é oferecida, atualmente, como uma mercadoria e a escola tornou-se uma empresa comercial à qual se paga pela obtenção de um serviço, nem sempre de qualidade.

Apesar de a educação abranger todos esses aspectos, a sociedade industrial capitalista tem direcionado o processo educativo essencialmente para adaptar os indivíduos ao mundo do trabalho, sobretudo às demandas do sistema econômico. A diversidade do processo de aprendizagem é, então, reduzida às determinações internas do capital ao mundo do trabalho, contrariando a 
orientação multidisciplinar das teorias educacionais já mencionadas. A educação deve valorizar, sobretudo, "uma construção coletiva que ocorre segundo determinações históricas e contextuais, jamais o fruto de vontades individuais e autônomas que seguem a exclusividade de suas forças interiores" (MAIA; JIMENEZ, 2013, p. 131).

Tais intervenções na educação apresentam-se como o maior trunfo para os problemas estruturais do "desenvolvimento" e do "progresso". Portanto, o surgimento e a consolidação da parceria entre os programas de combate à pobreza e de educação escolar não é gratuita. Mesclar as condições de pobreza com as habilidades cognitivas dos indivíduos parece estar entre as novas estratégias do capital, seja para promover seus interesses, seja para justificar a ocorrência da pobreza pela falta de educação. Isso fica expresso nas frases cotidianas de que "você é pobre porque não se qualificou" ou "você é pobre por que não tem educação". Atribuir a pobreza à falta de educação é diluir o problema e "repartir a culpa" entre toda a população. Problemas dessa natureza são inerentes à própria lógica capitalista, que prioriza o ensino técnico em detrimento de formação multidisciplinar que, grosso modo, abriria um leque maior de opções para o indivíduo durante o processo de formação humana.

A educação parece então ser a grande solução social a resolver a pobreza e as gritantes contradições do capitalismo. É o que se constata ao analisarmos os verbetes presentes no discurso neoliberal: pobreza, educação, segurança, desenvolvimento sustentável, capital humano, inclusão social, entre outros relacionados à formação dos indivíduos. A sociedade contemporânea está à mercê de um "macroprojeto" da burguesia, que exporta seus valores e interesses "universais" através da grande mídia e de diretrizes escolares. Algo semelhante ao que Ernest Gellner denominou de "homogeneização" de uma "cultura superior" liderada por uma "elite dominadora" (GELLNER, 1993). Portanto, a educação "estandardizada" e pragmática que Gellner ressalta na emergência da sociedade industrial amplia-se com o mundo globalizado, no qual diretrizes supostamente "universais" - como os "Quatro pilares da 
educação" - são disseminadas por programas educacionais financiados por bancos públicos internacionais.

O Brasil foi um dos países que adotaram tais diretrizes. Esta e inúmeras outras intervenções do BID fazem do Brasil um caso exemplar. Na perspectiva de Fonseca (1998), a influência de organismos multilaterais em território brasileiro não se restringe aos projetos em si, mas abrange a própria agenda educacional, na medida em que o Ministério da Educação incorpora as propostas internacionais às suas diretrizes. Trata-se de atividades das mais diversificadas, tais como escolha de municípios, elaboração de estudos estratégicos sob assessoria externa, definição de novas fontes de financiamento estaduais, municipais e federais, adoção de modalidades gerenciais de administração escolar e proposta de atuação em periferias urbanas e zonas rurais.

Fonseca (1998) analisa a invisibilidade e a não transparência desse tipo de projetos, posto que, em muitos casos, nem os próprios atores envolvidos (professores, gestores, alunos, etc.) têm conhecimento da origem externa dos mesmos. Tomando por base o estudo de acordos de cooperação financeira dos Bancos Mundial e do Brasil / MEC, durante os anos de 1980 (com participação financeira do BM entre 35\% a $40 \%$ ), a autora afirma:

Aqui cabe questionar os motivos que levaram à decisão por parte dos subsequentes governos brasileiros de firmar novos acordos. A meu ver, uma das explicações para tal atitude foi o mito que se criou em relação à capacidade técnica e financeira do Banco, devido, sobretudo, ao desconhecimento público sobre o real alcance do processo de cooperação externa (FONSECA, 1998, p. 233).

Retomando o pensamento de Gellner, constata-se na sociedade moderna uma elite que aspira legitimidade e poder político com a promoção de uma educação "estandardizada", incentivos à "semantização" do trabalho em prol das demandas do capital e valores e costumes norteados por uma noção contínua e desenfreada de "progresso". Essas características são acentuadas junto ao processo de globalização e podem ser constatadas nos dias atuais com as intervenções do BID na área educacional, que seguem um modelo padronizado de educação, mantém as demandas econômicas do capital em seus programas sociais, e incentivam 
a "semantização" do trabalho. Tudo regado pelo discurso de que a ciência e o "desenvolvimento" são as metas mais eficazes que sociedade e governo devem seguir, reafirmando a ideia de "progresso contínuo". A educação estaria à mercê dessa perspectiva de desenvolvimento acelerado. "O que nos preocupa aqui é a perspectiva de uma sociedade que se tornou dependente tanto do crescimento econômico como do conhecimento (estando os dois obviamente, inter-relacionados)." (GELLNER, 1993, p. 44).

Como visto, a base do problema exposto que envolve organismos multilaterais, governos e populações tem o seu eixo nas políticas educacionais e de combate à pobreza. A educação para os "pobres" seria então o foco central das macro-políticas, que por sua vez acabam por se refletir nas políticas públicas nacionais. Para Gellner, educação e "homogeneidade cultural" são fatores primordiais na formação de uma nação, sendo o "monopólio da educação" mais relevante do que o "monopólio legítimo da violência" do Estado weberiano:

O monopólio da educação legítima é agora mais importante e central do que o monopólio da violência legítima. E quando se compreende isto, então pode também ser compreendido o imperativo do nacionalismo, bem como as raízes que tem, não na natureza humana enquanto tal, mas num certo tipo de ordem social em vias de generalização (GELLNER, 1993, p. 59).

Portanto, se a educação está no cerne da construção das nacionalidades, a ingerência dos bancos públicos internacionais na área educacional afeta o processo de formação e afirmação dos Estados-nação. Constatando a relevante influência de organismos multilaterais nas diretrizes educacionais, podemos considerar que esses exercem certo "monopólio" nas políticas públicas aplicadas em boa parte do mundo ocidental, uma vez que os macros projetos nessa área social têm surtido fortes tendências a uma "homogeneização cultural", para assim atender às formas de serviços e trabalhos que o atual sistema econômico global demanda. 


\section{CONSIDERAÇÕES FINAIS}

Organismos multilaterais, como o BID e Banco Mundial, constituem elementos-chave para compreender o funcionamento da economia política internacional e sua repercussão nas políticas públicas no Brasil. Tais organismos propagam ideias neoliberais e, na atualidade, são instrumentos imprescindíveis à reprodução do capitalismo, cumprindo importante papel na "conquista de mentes". Para obter tal efeito, gozam de "autoridade e legitimidade" junto a governos, entidades empresariais, acadêmicos, meios de comunicação e organizações não governamentais, mediante suas ações como banco público internacional, ora financiando investimentos, ora prestando assistência técnica a programas sociais. Sua forte ingerência no setor educacional o "habilita" a um significativo papel no tocante à formação de seres humanos, a mais importante indústria da sociedade capitalista avançada, como observou Gellner.

Se considerarmos a possibilidade de haver um "pacto" internacional contemporâneo, esse englobaria a atuação de instituições multilaterais, a exemplo do BID e do Banco Mundial, e o poder de barganha de cada Estado-nação. As políticas públicas, em geral, e os programas educacionais e de combate à pobreza, que repercutem nas expectativas de vida e no destino das populações, são decididos tanto por essas instituições como pelos governos nacionais. As políticas públicas na área social afetam dois relevantes fatores constitutivos de uma nação: a educação, que forma o cidadão moderno, e a pobreza, que indica a condição do indivíduo como "incapaz" e "desqualificado", perante o sistema econômico produtivo. Ambos remetem à "autodeterminação" dos povos, um termo polêmico, presente tanto no ideário das lutas nacionais, como no discurso das agências multilaterais.

O desenvolvimento das sociedades ocidentais, a partir da Independência dos Estados Unidos e da Revolução Francesa, com a luta pelos direitos humanos e a emergência da República, vão aproximando a "nação", de origens cultural/ontológica, ao Estado, garantidor da soberania política, resultando na mais significativa instituição das sociedades modernas: o Estado-Nação. É esse fenômeno social multifacetário, cujo estudo demanda necessariamente 
abordagem transdisciplinar e compreende articulação de inúmeros campos do saber, que está no centro da discussão deste artigo, ao constatar que os organismos multilaterais fazem parte do processo formador das nações.

$\mathrm{Na}$ busca pela soberania nacional e pela autonomia perante a comunidade global, a educação é mecanismo essencial de controle dos povos, sendo possível que seja utilizada tanto para a reprodução de valores capitalistas, quanto para a formação humanística. Nos esforços empreendidos para o desenvolvimento nacional, as diretrizes educacionais dos governos podem preparar cidadãos "cultos e ativistas" que lutem pelo futuro de sua nação ou privilegiar a qualificação de mão-de-obra "capacitada e apta" a integrar o sistema produtivo capitalista. Contudo, nota-se a predominância de uma tendência tecnicista/profissionalizante no paradigma educacional almejado pelo capitalismo, vistos os macro interesses em produzir e reproduzir mão de obra adequada às demandas da produção.

As implicações dos programas do BID e do Banco Mundial na área educacional são bastante amplas e diversificadas e o caso da conferência de Jomtein exemplifica bem o tipo de interferência que este estudo aborda. A elaboração e difusão de documentos, como o relatório "Educação: um tesouro e descobrir", juntamente com as supostas diretrizes "universais" contidas nos "Quatro Pilares da Educação", indicam com clareza o conteúdo ideológico que as instituições financeiras internacionais pretendem levar adiante em seu projeto de formação de "capital humano".

Raciocinar com as categorias teóricas de Gellner nos permite chegar a algumas descobertas pertinentes ao campo das políticas públicas: a "estandardização" da educação estaria sendo promovida globalmente pelos bancos públicos internacionais com base nas diretrizes estabelecidas pelos "Quatros pilares da Educação"; a "semantização do trabalho" teria se intensificado com o modelo de produção crescentemente automatizada de bens e serviços, o qual vem tornando o trabalho cada vez mais abstrato e peculiar a esse sistema.

Trazendo o problema à realidade latino-americana e brasileira, podemos destacar as articulações políticas/financeiras do BID e Banco Mundial na área educacional e no combate à pobreza, além de seus impactos no planejamento de políticas públicas nacionais, 
com foco especial para as interferências do BID na educação brasileira, na década de 2000. Os reflexos desse organismo multilateral podem ser detectados, por exemplo, no Plano Plurianual (PPA) e da Lei de Diretrizes e Bases da Educação Nacional (LDB). Visto que o PPA representa a bússola que conduz as políticas da União brasileira, e a LDB a base do sistema educacional do país. (FONSECA, 1998).

Então, se o BID tem "legitimidade" para interferir no cerne do principal elemento formador da sociedade, o ser humano, é cabível concluir que essa instituição está implicada diretamente na construção da nacionalidade. Porém, "poder e autoridade" nem sempre se conquistam com armas e violência física, mas com discursos e práticas em torno de "erradicar a pobreza", do "capital humano", "progresso incessante", e "desenvolvimento econômico". Como buscamos demonstrar no artigo, pobreza e educação são elementos essenciais para a legitimação e o reconhecimento dos organismos multilaterais. Essas duas categorias também auxiliam a mitigar qualquer traço negativo na imagem do BID e do Banco Mundial, encobrindo, em parte, a reputação destes como agentes que visam lucros, e projetando a de que são portadores de uma "missão humanitária".

A experiência desse estudo acerca das relações entre bancos públicos internacionais e as nações, assim como de uma instituição abrangente como o Banco Interamericano de Desenvolvimento, demonstrou ser tarefa árdua: documentos e funcionários da instituição são de difícil acesso, a divulgação sobre sua atuação na mídia é superficial e há carência de estudos acadêmicos sobre o tema. Quase todas as informações acerca da instituição estão concentradas no seu website, não havendo informações detalhadas sobre os programas educacionais, objetos deste estudo. Isso, obviamente, comprometeu uma análise mais apurada, visto que a maioria das informações provém de fonte oficial.

Apesar das dificuldades e limitações encontradas na realização deste estudo, acreditamos que ele venha a contribuir de alguma forma para um maior entendimento de ações de organismos internacionais nas políticas públicas, dos estreitos laços entre os conceitos de pobreza e educação nas sociedades capitalistas, e das relações complexas entre tais organismos e os Estados nacionais. 


\section{REFERÊNCIAS}

DELORS, J. Educação: um tesouro a descobrir. São Paulo: Cortez; Brasília, DF. MEC/UNESCO, 1998.

EVANGELISTA, E. G. dos S. Educação e mundialização. Goiânia: Editora da UFG, 1997.

FARIAS, F. A. A pobreza e o Banco Mundial: conceitos, estratégias e metodologias. Monografia. Universidade Estadual do Ceará, 2007.

FONSECA, M. O financiamento do Banco Mundial à educação brasileira: vinte anos de cooperação internacional. In: DE TOMMASI, L.; WARDE, M. J.; HADDAD, S. (Orgs.). O Banco Mundial e as políticas educacionais. 2. ed. São Paulo: Cortez, 1998. p. 229-251.

GELLNER, E. O advento do nacionalismo e sua interpretação: os mitos da nação e da clase. In: GOPAL BALAKRISHNAN (Org.). Um mapa da questão nacional. Rio de Janeiro: Contraponto, 2000.

GELLNER, E. Nação e nacionalismo. Lisboa: Gradiva, 1993.

LA TAILlE, Y.; DANTAS, H.; OLIVEIRA, M. K. de. Piaget, Vygotsky, Wallon: teorias psicogenéticas em discussão. 24. ed. São Paulo: Summus, 1992.

LEHER, R. Um novo senhor da educação? A política educacional do Banco Mundial para a periferia do capitalismo. Revista Outubro, São Paulo, n. 1, p. 19-30. 1999.

LOPÉZ. Maria Margarita. A educação e sua incidência sobre a pobreza na Colômbia. In: Educação e pobreza na América Latina. Cadernos Adenauer VII, $\mathrm{n}^{\circ}$ 2. Rio de Janeiro: Fundação Konrad Adenauer, junho 2005. p. $9-13$

MAIA, O.; JIMENEZ, S. A chave do saber: um exame crítico do novo paradigma educacional concebido pela ONU. In: SANTOS, D.; JIMENEZ, S.; VIANA, C. M. Q. Q.; RABELO, J. Educação pública, formação profissional e crise do capitalismo contemporâneo. Fortaleza: EdUECE, 2013. p. 113-134.

RODRIGUEZ, J. A. Educação e desenvolvimento. In: SANTOS, D.; JIMENEZ, S.; VIANA, C. M. Q. Q.; RABELO, J. Educação pública, formação profissional e crise do capitalismo contemporâneo. Fortaleza: EdUECE, 2013. p. .73-88

WORLD BANK. Priorities and strategies for education. Washington, D.C., 1990. 